\title{
EVALUATION OF ANTI-INFLAMMATORY, ANALGESIC, ANTIPYRETIC EFFECT OF EICOSANE, PENTADECANE, OCTACOSANE, AND HENEICOSANE
}

\author{
PATRICK NWABUEZE OKECHUKWU*
}

Department of Biotechnology, Faculty of Applied Science, UCSI University No. 1, Jalan Menara Gading, UCSI Heights, (Taman Connaught) Cheras 56000 Kuala Lumpur, Malaysia. Email: patrickn@ucsiuniversity.edu.my

Received: 02 November 2019, Revised and Accepted: 25 January 2020

\section{ABSTRACT}

Objective: Marantodes pumilum (MP) is a plant widely used in traditional medicine in the Southeast Asian region and been reported to possess antiinflammatory, analgesic, antipyretic, and antiulcer properties. The aim of the study is to identify the bioactive phytochemicals present in the purified leaf extract of MP using gas chromatography mass spectrometry (GC-MS), and to determine their anti-inflammatory, analgesic, and antipyretic effect in a rat model.

Methods: A dichloromethane crude extract of MP was partially purified using column chromatography, and the bioactive compounds were identified using GC-MS. The anti-inflammatory, analgesic, and antipyretic activities of the identified bioactive compounds were evaluated using formalin, carrageenan, acetic acid, and brewer's yeast to induce the rats.

Results: Eicosane, pentadecane, octacosane, and heneicosane were identified as bioactive compounds in purified leaf extract of MP. These bioactive compounds did not show any toxicity on the rats at $1000 \mathrm{mg} / \mathrm{kg}$. There was no mortality, and no apparent behavioral, physiological, and morphological changes of the internal organs occurred. They exhibited a very significant $(\mathrm{p}<0.05)$ dose-dependent inhibition of acetic acid-induced writhing, formalin-induced paw licking, carrageenan-induced paw edema, and brewer's yeast-induced pyrexia.

Conclusions: Eicosane and pentadecane were able to show very strong anti-inflammatory, analgesic, and antipyretic effects. The observed effects of the bioactive compounds are similar to previous reports on crude and partially purified leaf extract of MP. The finding suggests that eicosane and pentadecane maybe the major bioactive compounds present in the purified leaf extract of MP.

Keywords: Marantodes pumilum, Anti-inflammatory, Analgesic, Antipyretic, Toxicity.

(C) 2020 The Authors. Published by Innovare Academic Sciences Pvt Ltd. This is an open access article under the CC BY license (http://creativecommons. org/licenses/by/4. 0/) DOI: http://dx.doi.org/10.22159/ajpcr.2020.v13i4.36196

\section{INTRODUCTION}

Inflammation is a normal host defense mechanism that protects the host from infection and other insults; it initiates pathogen killing as well as tissue repair processes and helps to restore homeostasis at infected or damaged sites. It is characterized by redness, swelling, heat, pain, and loss of function, and involves interactions among many cell types and the production of, and responses to, a number of chemical mediators. Remedies of inflammation using medicinal plants are becoming popular, and it is used by a majority of the world's population. The efficacy of medicinal plants in the management of diseases is indubitable. The projection from the World Health Organization is that about $80 \%$ of the population of developing countries continues to use traditional medicine in primary medical problems. Several plants are typically used without considering the toxicity and pharmacological aspects of extract and phytochemicals present. The toxicity of herbal preparation and its bioactive constituents is usually unknown, and the population does not care, believing that if the material has been used so far, it should be devoid of toxicity [1]. It is very important to extract information on the toxicity of the plants and its bioactive compounds [2]. Since conventional anti-inflammatory drugs have not been successful in some inflammatory processes, there is an urgent need to have new and safe anti-inflammatory agents [3]. Attention is being focused on the investigation of the efficacy of plant-based drugs used in traditional medicine [4].

Marantodes pumilum (MP) is a plant commonly found in the Southeast Asian region. It is an herbaceous shrub with creeping rhizome that roots from the stem. MP has been reported to displace estradiolbinding antibodies [5] and modulates postmenopausal adiposity through the initiation of a lipolysis process in adipose tissues [6]. A crude and purified dichloromethane (DCM) leaf extract of MP has been reported to possess anti-inflammatory, analgesic, and antipyretic effects [7]. There has not been any pharmacological report on the identification of bioactive constituents in the crude and purified DCM leaf extract of MP. Gas chromatography/mass spectrometry (GC/MS) has become the choice method for identifying volatile compounds in complex mixtures [8]. The popularity of volatile compounds such as essential oils has gained interest with reported properties such as antimicrobial, antifungal, antioxidant, and free-radical scavenging activity [9-11]. Therefore, the present research aims to identify the bioactive phytochemicals present in the purified leaf extract of MP using GC-MS, and to determine the anti-inflammatory, analgesic, and antipyretic effects of the identified bioactive compounds in a rat model.

\section{EXPERIMENTAL}

\section{Preparation of plant extract}

The leaves of MP were purchased from the University Putra Malaysia, Serdang Selangor Darul Ehsan Malaysia. The plant was identified by Dr. Shamsul Khamis, a research officer (plant taxonomist) at the laboratory of Natural Products, Institute of Bioscience University Putra Malaysia. The leaves of MP (1 kg) were air-dried and powdered using a dry mill with $0.5 \mathrm{~mm}$ mesh size. $0.5 \mathrm{~kg}$ of the power was macerated for $48 \mathrm{~h}$ at room temperature in $5 \mathrm{~L}$ of DCM. The filtrate was concentrated using a rotary evaporator (BUCHI Rotavapor R-200, Switzerland) at a temperature of $35-40^{\circ} \mathrm{C}$. After the evaporation process, a dark green residue was collected and left to dry in a fume cupboard [12]. 


\section{Partial purification}

A column $(34 \mathrm{~cm} \times 3 \mathrm{~cm})$ was packed with silica gel $(50 \mathrm{~g})$ by pouring dry silica into a beaker of initial eluent of hexane $(200 \mathrm{ml})$ to make slurry. The slurry was carefully poured into the column, previously for a quarter filled with hexane with the aid of a funnel. $20 \mathrm{~g}$ of DCM extract was loaded into the column and allowed to set before running the column. The partial purification of the DCM extract by column chromatography used a $42 \mathrm{~cm} \times 2.5 \mathrm{~cm}$ vertical column equipped with a stop cock and glass frit to support the silica gel, pore size $60 \AA$, 200-400 mesh. $100 \%$ hexane was used to pre-elute the column. A decreasing polarity solvent ratio $(100 \%$ hexane $(\mathrm{Hx})-\mathrm{Hx}$ : Ethyl acetate (EA) - EA: Methanol $(\mathrm{MeOH})-100 \% \mathrm{MeOH})$ was used to obtain Fraction E (60:40 $\mathrm{Hx}$ : EA to $100 \% \mathrm{MeOH})$. The fractions were collected based on their chromatogram profiles analyzed on TLC plates Silica gel 60 F254 and mobile phase 60:40 Hx: EA.[12]

\section{GC-MS}

$10 \mathrm{mg}$ of purified leaf extract of MP was dissolved in high-performance liquid chromatography grade methanol and was filtered through a $0.45 \mu \mathrm{m}$ Millipore sterile syringe filter, before analysis. GC-MS was performed using the Agilent instrument model (5973). A HP-5MS 5\% Phenyl Methyl Silox column with $30 \mathrm{~m}$ in length, $0.25 \mu \mathrm{m}$ in diameter, and beta value of $250 \mu \mathrm{m}$ was used.

\section{Animal model}

Male Sprague-Dawley rats weighing 200-220 g, obtained from the Institute of Medical Research, were used for the investigations. They were housed in groups of six in standard cages in animal holdings units at UCSI University, Kuala Lumpur, Malaysia. They were maintained under standard environmental conditions, fed with standard pellet diet and received water ad libitum. They were left to acclimatize for 2 weeks before the commencement of the experiment. All experiments were carried out in accordance with the UCSI University Ethical Guidelines on the usage of Laboratory Animals.

\section{Acute toxicity test}

The maximum of six Sprague-Dawley rats of three males and three females with an average weight of $220 \mathrm{~g}$ were fasted with only water provided ad libitum for $2 \mathrm{~h}$ before the administration of drugs. A single dose of $1000 \mathrm{mg} / \mathrm{kg}$ body weight of eicosane, pentadecane, octacosane, or heneicosane prepared in $10 \% \mathrm{v} / \mathrm{v}$ hexane and saline, was orally administrated for 14 consecutive days. The animals were weighed before and after the administration of the compounds for the acute toxicity test. The animals were observed for any behavioral effects such as hyper excitability and depression or physiological effects such as diarrhea, salivation, motor impairment, as well as the incidence of mortality for $30 \mathrm{~min}, 4 \mathrm{~h}$ and daily for 14 days after the administration of the compounds [13]. After 14 days of treatment and observations, the animals were sacrificed, and the internal organs such as stomach, small intestine, kidneys, and liver were collected. The organs were anatomically examined for morphological changes and weight. The data were compared with the normal rat's organs.

\section{Acetic acid-induced writhing}

An acetic acid-induced writhing test was done using the method, according to Okechukwu and Ikujuni [14], for the analgesic actions of eicosane, pentadecane, octacosane, and heneicosane. Each rat in groups of six was injected intraperitoneally an $0.6 \%$ aqueous solution of acetic acid ( $10 \mathrm{ml} / \mathrm{kg}$ body weight), $1 \mathrm{~h}$ after receiving oral (p.o.) administered saline $(1 \mathrm{ml})$ as the negative control, eicosane, pentadecane, octacosane, and heneicosane (5 and $10 \mathrm{mg} / \mathrm{kg}$ ), or indomethacin $(10 \mathrm{mg} / \mathrm{kg})$, an anti-inflammatory drugs as positive control. Immediately after the acetic acid injection, each animal was placed in a transparent observation cage and the number of writhes per rat was counted for $30 \mathrm{~min}$. The writhing activity comprised constriction of the abdominal muscles together with a stretching of the hind limbs. The percentage of inhibition of writhing was calculated using the equation below:

\author{
Mean writhing count \\ $\%$ Analgesic activity $=\frac{\text { (Controlgroup }- \text { Treated group) }}{\text { Mean writhing count of }} \times 100$ \\ control group
}

\section{Formalin-induced paw licking}

Based on the method described by Okechukwu et al., Okechukwu and Ikujuni $[7,14]$, a formalin-induced paw licking test was exploited to determine the analgesic actions of eicosane, pentadecane, octacosane, and heneicosane. Rat was injected with $50 \mu \mathrm{l}$ of $2.5 \%$ formalin in $0.9 \%$ of saline solution into the subplantar surface of the left hind paw, $1 \mathrm{~h}$ after the administration of $0.9 \%$ saline, $100 \mathrm{mg} / \mathrm{kg}$ of aspirin and eicosane, pentadecane, octacosane, and heneicosane ( 5 and $10 \mathrm{mg} / \mathrm{kg}$ ). Rats were then observed for $30 \mathrm{~min}$, and the time spent licking the paw was recorded in two phases. The data were expressed as total licking time in the early phase (0-5 min) and the late phase (15-30 min) after formalin injection. Percentage of inhibition was calculated using the equation below:

$\%$ Anti - inflammatory effect $=\frac{\begin{array}{c}\text { Mean paw licking, jecking, flexing } \\ \text { in (Controlgroup }- \text { Treatedgroup })\end{array}}{\begin{array}{c}\text { Meanpawlicking, jecking, } \\ \text { flexing incontrol group }\end{array}} \times 100$

\section{Carrageenan-induced paw edema}

\section{Carrageenan-induced paw edema}

The anti-inflammatory activity of eicosane, pentadecane, octacosane, and heneicosane was evaluated using carrageenan-induced paw edema, as described by Okechukwu and Ikujuni [14]. The rats were fasted overnight with water ad libitum, and the basal volume of right hind paw was measured before the administration of drugs by using a plethysmometer. Acute inflammation was induced by subplantar injection in the right hind paw of the rats, with $0.1 \mathrm{ml}$ of $(1.0 \% \mathrm{w} / \mathrm{v})$ carrageenan suspension in $0.9 \% \mathrm{NaCl}$. The animals were orally administered with vehicle (saline), indomethacin (10 mg/kg), eicosane, pentadecane, octacosane, and heneicosane ( 5 and $10 \mathrm{mg} / \mathrm{kg}$ ) $1 \mathrm{~h}$ before the carrageenan injection. The thickness of hind paw was monitored and measured at 1, 2, 3, 4, and $5 \mathrm{~h}$ after the carrageenan injection using the plethysmometer [14]. Percentage of inhibition was calculated using the equation below:

$$
\begin{gathered}
\text { Mean paw volume in } \\
\% \text { Inhibition }=\frac{(\text { control group }- \text { Treated group })}{\text { Mean paw volume in control group }} \times 10 \mathrm{C}
\end{gathered}
$$

\section{Yeast-induced pyrexia}

Hyperpyrexia was induced by subcutaneous administration of a $(15 \% \mathrm{w} / \mathrm{v})$ brewer's yeast suspension in $0.9 \% \mathrm{NaCl}$ in a volume of $0.1 \mathrm{ml} / 10 \mathrm{~g}$ of bodyweight after the initial rectal temperature of each rat was measured and recorded using a digital clinical thermometer. Twenty-four hours after induction of hyperpyrexia, any animals that showed a minimal increase of $0.5^{\circ} \mathrm{C}$ in rectal temperature were selected for the experiment. The animals were orally administered with vehicle (saline), indomethacin $(10 \mathrm{mg} / \mathrm{kg})$, eicosane, pentadecane, octacosane, and heneicosane ( 5 and $10 \mathrm{mg} / \mathrm{kg}$ ). The rectal temperature of each rat was measured at $1 \mathrm{~h}$ interval for $5 \mathrm{~h}$ [14]. The percentage of temperature reduction was calculated using the following equation:

$$
\% \text { Antipyretic effect }=\frac{(\text { Yeast induced pyrexia }- \text { Post treatment })}{\text { (Yeast induced pyrexia })} \times 100
$$

\section{Statistical analysis}

Data were expressed as mean \pm standard deviations (SD). Statistically significant differences between groups were measured using a oneway analysis of variance followed by Dunnett's test. Statistical analysis 
was performed using Minitab ${ }^{\circledR}$ Release 17 (Minitab Inc., US). Values of ${ }^{*} \mathrm{p}<0.05$ were considered statistically significant

\section{RESULTS AND DISCUSION}

Preparation of plant extract and partial purification

The crude extract yield from $1 \mathrm{~kg}$ leaf of MP was $50 \mathrm{~g}$ after the extraction process. DCM was the solvent used for the crude extraction. Partial purification yielded five different fractions A-E.

\section{GC-MS}

Fraction A was subjected to GC-MS because it is the fraction that retained bioactivity. The major bioactive compounds that were identified in this partially purified fraction A from the MP extract were: Phthalic esters; Bis(2-propylpentyl) phthalate and Bis(2-propylpentyl) phthalate (RT: 20.65, 17.8\%), branched alkane hydrocarbons; Heneicosane, Hexadecane,1-iodo, Octacosane (RT:34.756, 11.72\%), Pentadecane, Heptadecane and Heptacosane (RT: 23.142, 7.89\%), tricosane and eicosane (RT: $26.902,5.25 \%$ ) and terpenes; and $\beta$-amyrin and Urs-12en-3-one (RT: 28.361, 6.84\%). The molecular weight and nomenclature were taken from the National Institute of Standards and Technology, PubChem, ChemBook, and ChemSpider. The constituents with peak area $>2 \%$ with their CAS number, molecular weight, molecular compound, retention time, and structure are reported in Table 1, Figs. 1a and 1b. The major constituents sum up to $49.5 \%$ of the total constituents.

\section{Toxicity test}

Oral administration of eicosane, pentadecane, octacosane, and heneicosane at $1000 \mathrm{mg} / \mathrm{kg}$ to rats did not cause any behavioral effects such as hyper excitability and depression or physiological effects such as diarrhea, salivation, and motor impairment. There was no mortality recorded throughout the 14 days treatment. The result shows that eicosane, pentadecane, octacosane, and heneicosane have no apparent toxicity to the rats at a concentration of $1000 \mathrm{mg} / \mathrm{kg}$. Acute toxicity studies are widely used to ensure the safety of new drugs using animal models. They are performed to classify and label the potential hazard categories and estimate the concentration or dose required to cause toxicity [16]. Such assessment is important in the selection of a starting dose for Phase 1 human studies and provides the information relevant to avoid acute overdosing. Acute toxicity studies determine the LD50 values that provide indices of potential types of drug activities [17]. Lethal dosage (LD50) is the concentration of a substance or drug that will lead to the deaths of $50 \%$ of the population [18]. Eicosane, pentadecane, octacosane, and heneicosane at $1000 \mathrm{mg} / \mathrm{kg}$ did not show toxicity to the rats and are adjudicated to be safe to enter the next phase of the study as drug candidates.

\section{Acetic acid-induced writhing}

The oral administration of increasing concentration (5 and $10 \mathrm{mg} / \mathrm{kg}$ ) of eicosane, pentadecane, octacosane, and heneicosane showed a significant reduction $(\mathrm{p}<0.05)$ in the number of writhing induced by acetic acid compared to the negative control. Eicosane showed the highest effect, followed by pentadecane. The results of acetic acid-induced writhing are shown in Fig. 2.

Acetic acid-induced writhing test is widely used to evaluate compounds with analgesic potential [19]. Intraperitoneal injection of acetic acid causes constriction of the abdominal muscle, which was accompanied by the twisting of the trunk followed by stretching of the hind limbs [20]. The acetic acid injection also results in the induction of inflammatory responses in subcutaneous and muscular layers of the abdominal wall [21]. These responses are the result of tissue damage

Table 1: Gas chromatography/mass spectrometry analysis of the fraction A of extract of Marantodes pumilum

\begin{tabular}{|c|c|c|c|c|c|c|}
\hline S. No. & RT & Compounds & CAS registry & $\begin{array}{l}\text { Molecular } \\
\text { compound }\end{array}$ & MW & PA\% \\
\hline 1 & 3.762 & $\begin{array}{l}\text { 1-Butene, 2,3,3-trimethyl- } \\
\text { 2-Pentene, 4,4-dimethyl-, (Z)- } \\
\text { 2-Pentene, 4,4-dimethyl-, (E)- }\end{array}$ & $\begin{array}{l}594-56-9^{\text {(NIST) }} \\
762-63-0^{\text {(NIST) }} \\
690-08-4^{\text {(NIST) }}\end{array}$ & $\begin{array}{l}\mathrm{C}_{7} \mathrm{H}_{14} \\
\mathrm{C}_{7} \mathrm{H}_{14} \\
\mathrm{C}_{7} \mathrm{H}_{14}\end{array}$ & $\begin{array}{l}98.186 \\
98.186 \\
98.186\end{array}$ & 2.16 \\
\hline 2 & 14.302 & 2-Pentadecanone, 6,10,14-trimethyl & $502-69-2^{\text {(NIST) }}$ & $\mathrm{C}_{18}^{\prime} \mathrm{H}_{36} \mathrm{O}$ & 268.478 & 4.46 \\
\hline 3 & 15.097 & $\begin{array}{l}\text { 1-Octacosanol } \\
\text { Docos-1-ene } \\
\text { 9-Nonadecene }\end{array}$ & $\begin{array}{l}29739970^{(\mathrm{CS})} \\
1599-67-3^{\text {(NIST) }} \\
31035-07- \\
1^{\text {(NIST) }}\end{array}$ & $\begin{array}{l}\mathrm{C}_{30}^{18} \mathrm{H}_{57}^{30} \mathrm{~F}_{3} \mathrm{O}_{2} \\
\mathrm{C}_{22} \mathrm{H}_{44} \\
\mathrm{C}_{19} \mathrm{H}_{38}\end{array}$ & $\begin{array}{l}506.768 \\
308.585 \\
266.505\end{array}$ & 2.61 \\
\hline 4 & 15.372 & Isophytol & $505-32-8^{\text {(NIST) }}$ & $\mathrm{C}_{20} \mathrm{H}_{40} \mathrm{O}$ & 296.351 & 2.96 \\
\hline 5 & 16.877 & Tetracosyl heptafluorobutyrate & $29739954^{(\mathrm{CS})}$ & $\mathrm{C}_{28}^{20} \mathrm{H}_{49}^{40} \mathrm{~F}_{7} \mathrm{O}_{2}$ & 550.676 & 2.38 \\
\hline 6 & 17.661 & $\begin{array}{l}\text { Ethanol, 2-(octadecyloxy)- } \\
\text { 1-(4-Bromobutyl)-2-piperidinone } \\
\text { 1-Decanol, 2-hexyl- }\end{array}$ & $\begin{array}{l}2136-72-3^{\text {(NIST) }} \\
467195^{\text {(CS) }} \\
2425-77-6^{\text {(NIST) }}\end{array}$ & $\begin{array}{l}\mathrm{C}_{20} \mathrm{H}_{42} \mathrm{O}_{2} \\
\mathrm{C}_{9} \mathrm{H}_{16} \mathrm{BrNO} \\
\mathrm{C}_{16} \mathrm{H}_{34} \mathrm{O}\end{array}$ & $\begin{array}{l}314.546 \\
234.133 \\
242.441\end{array}$ & 2.03 \\
\hline 7 & 18.530 & Tricosane & $638-67-5^{(\mathrm{NIST})}$ & $\mathrm{C}_{23}^{16} \mathrm{H}_{48}^{34}$ & 324.627 & 2.56 \\
\hline 9 & 20.659 & $\begin{array}{l}\text { Bis(2-ethylhexyl) phthalate } \\
\text { Bis(2-propylpentyl) phthalate }\end{array}$ & $\begin{array}{l}117-81-7^{(\mathrm{NIST})} \\
166657^{(\mathrm{CS})}\end{array}$ & $\begin{array}{l}\mathrm{C}_{24}^{23} \mathrm{H}_{38}^{48} \mathrm{O}_{4} \\
\mathrm{C}_{24} \mathrm{H}_{38} \mathrm{O}\end{array}$ & $\begin{array}{l}390.556 \\
390.556\end{array}$ & 17.80 \\
\hline 10 & 22.513 & $\begin{array}{l}\text { i-Propyl 9-octadecenoate } \\
\text { Octadec-9-enoic acid }\end{array}$ & $\begin{array}{l}111-59-1^{(\mathrm{PC})} \\
2027-47-6^{(\mathrm{NIST})}\end{array}$ & $\begin{array}{l}\mathrm{C}_{21}^{24} \mathrm{H}_{40}^{38} \mathrm{O}_{2}^{4} \\
\mathrm{C}_{18} \mathrm{H}_{34} \mathrm{O}_{2}\end{array}$ & $\begin{array}{l}324.541 \\
282.461\end{array}$ & 2.46 \\
\hline 11 & 23.142 & $\begin{array}{l}\text { Pentadecane } \\
\text { Heptadecane, 9-octyl- } \\
\text { Heptacosane, 1-chloro- }\end{array}$ & $\begin{array}{l}629-62-9^{(\mathrm{NIST})} \\
7225-64-1^{\text {(NIST) }} \\
62016-79- \\
9^{\text {(NIST) }}\end{array}$ & $\begin{array}{l}\mathrm{C}_{15} \mathrm{H}_{32}^{34} \\
\mathrm{C}_{25} \mathrm{H}_{52} \\
\mathrm{C}_{27} \mathrm{H}_{55} \mathrm{Cl}\end{array}$ & $\begin{array}{l}212.415 \\
352.680 \\
415.179\end{array}$ & 7.89 \\
\hline 12 & 24.756 & $\begin{array}{l}\text { Heneicosane } \\
\text { Hexadecane, 1-iodo- } \\
\text { Octacosane }\end{array}$ & $\begin{array}{l}629-94-7^{\text {(NIST) }} \\
544-77-4^{\text {(NIST) }} \\
630-02-4^{\text {(NIST) }}\end{array}$ & $\begin{array}{l}\mathrm{C}_{21} \mathrm{H}_{44} \\
\mathrm{C}_{16} \mathrm{H}_{33} \mathrm{I} \\
\mathrm{C}_{28} \mathrm{H}_{58}\end{array}$ & $\begin{array}{l}296.574 \\
352.338 \\
394.760\end{array}$ & 11.72 \\
\hline 13 & 26.902 & Eicosane & $112-95-8^{(\mathrm{NIST})}$ & $\mathrm{C}_{20}^{28} \mathrm{H}_{42}^{58}$ & 282.548 & 5.25 \\
\hline 14 & 27.932 & $\begin{array}{l}\text { 1,3-Dithiolane, 2-(28-norurs-12-en -17-yl)- } \\
\text { 3,7,11-Trimethyl-dodeca-2,4,6,10-t etraenal } \\
\text { (22E)-3',7 } 3 \text {-Dihydrocycloprop[7,8]-5 } \alpha \text {-ergost-22-en-3-one }\end{array}$ & $\begin{array}{l}473220^{(\mathrm{CS})} \\
23255776^{(\mathrm{CS})} \\
53755-18-3^{(\mathrm{CB})}\end{array}$ & $\begin{array}{l}\mathrm{C}_{32} \mathrm{H}_{52} \mathrm{~S}_{2} \\
\mathrm{C}_{15} \mathrm{H}_{22} \mathrm{O} \\
\mathrm{NR}\end{array}$ & $\begin{array}{l}500.885 \\
218.335 \\
\text { NR }\end{array}$ & 2.65 \\
\hline 15 & 28.361 & $\begin{array}{l}\beta \text {-Amyrin } \\
\text { Urs-12-en-3-one }\end{array}$ & $\begin{array}{l}559-70-6^{(\text {NIST) }} \\
532729^{(\mathrm{CS})}\end{array}$ & $\begin{array}{l}\mathrm{C}_{30} \mathrm{H}_{50} \mathrm{O} \\
\mathrm{C}_{30} \mathrm{H}_{48} \mathrm{O}\end{array}$ & $\begin{array}{l}426.717 \\
424.702\end{array}$ & 6.84 \\
\hline
\end{tabular}

*RT: Retention time, "PA \%: Peak area percentage, NR: Not reported, MW: Molecular weight (corrected to three decimal places), NIST: National Institute of Standards and Technology, PC: PubChem, CB: ChemBook, CS: ChemSpider 


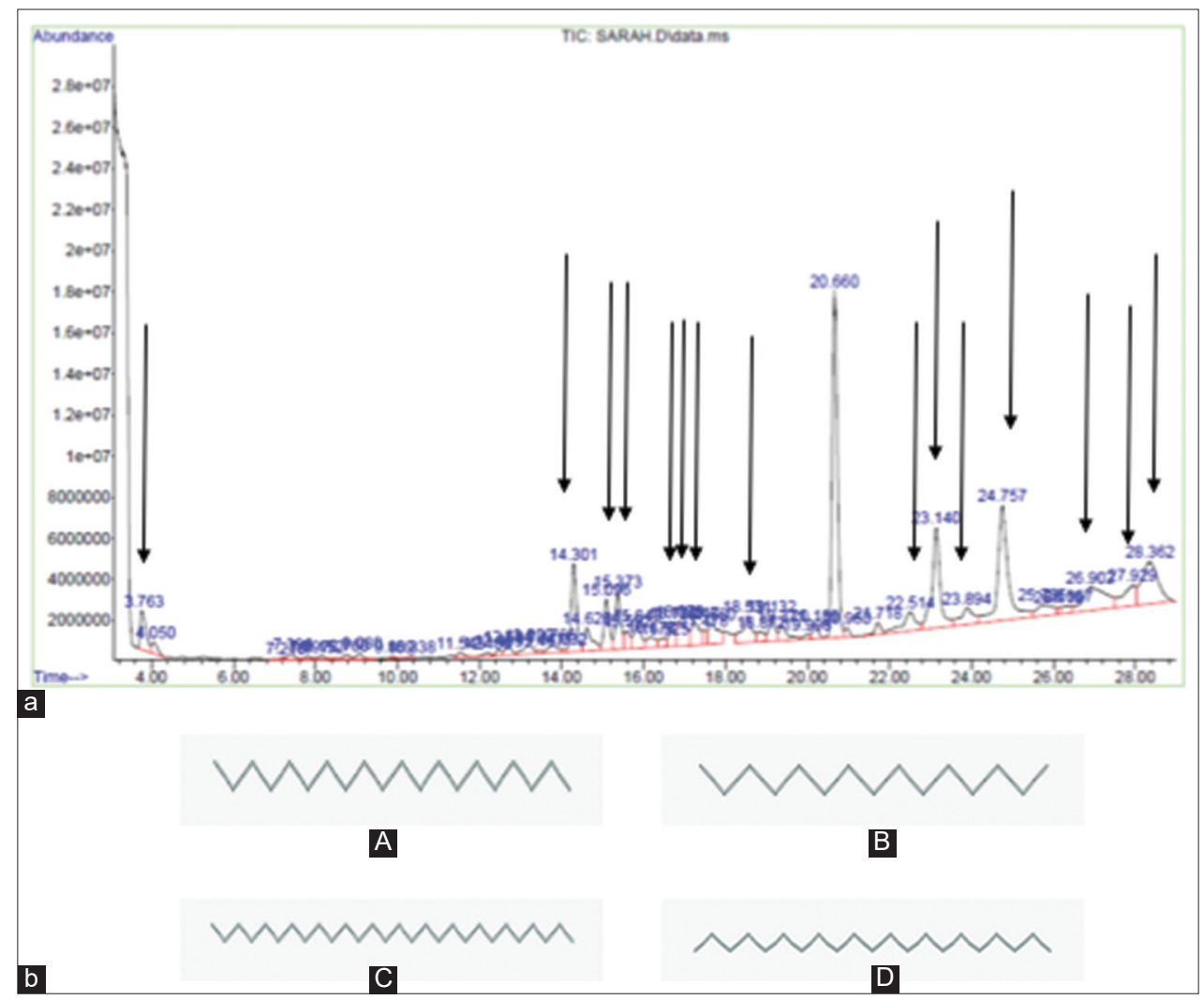

Fig. 1: (a) Gas chromatography/mass spectrometry analysis of the fraction A of extract of Marantodes pumilum (b) chemical structure of $A=$ Eicosane, $B=$ Pentadecane $C=$ Octacosane, and $D=$ Heneicosane

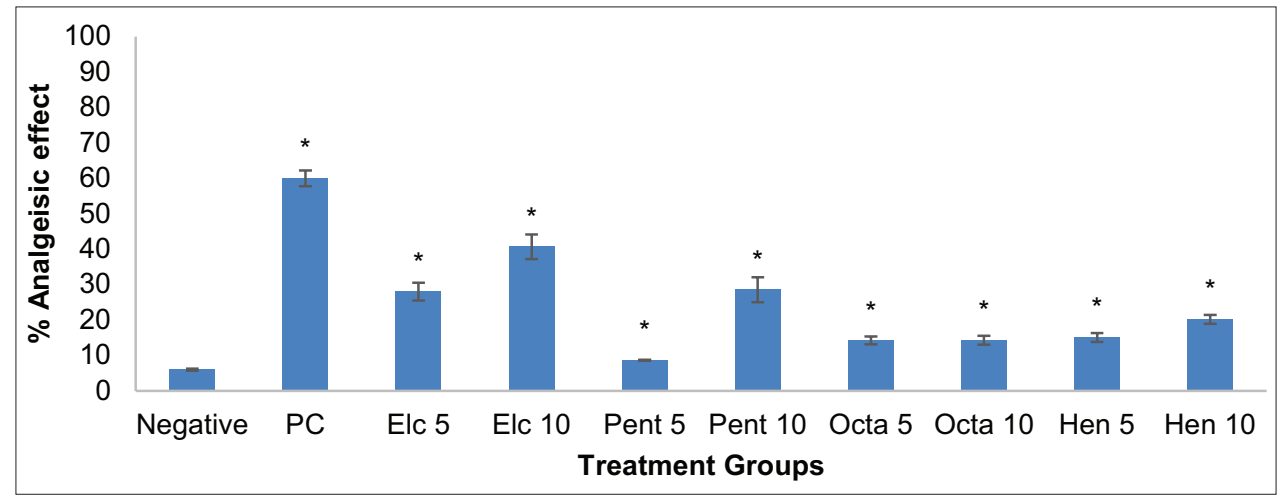

Fig. 2: Percentage analgesic effect on animals orally treated with saline solution (negative control), eicosane (Eic), pentadecane (Pent), octacosane (Octa), heneicosane (Hen) doses $(5$ and $10 \mathrm{mg} / \mathrm{kg})$, and indomethacin (PC) $(10 \mathrm{mg} / \mathrm{kg})$ before the acetic acid (0.6\%, i.p.). Values are expressed as mean \pm Standard deviation, $n=6$, the statistical significance by one-way analysis of variance followed by Dunnett's test. Values are significant at ${ }^{*} \mathrm{p}<0.05$ compared to negative control when no drugs were given

and sensitization of nociceptive receptors to prostaglandins (PGs). They are also assumed to involve local peritoneal receptors and be mediated by peritoneal mast cells, acid-sensing ion channels, and the PG pathways. Prostaglandins have been widely reported to play an important role in the nociceptive mechanism [22]. Reports have shown that intraperitoneal injection of acetic acid triggers the release of several other mediators such as neurotransmitters, tumor necrosis factor- $\alpha$ (TNF- $\alpha$ ), interleukin-1 $\beta$ (IL $\beta$ ) and IL-8, histamine, kinins, acetylcholine, and substance $\mathrm{P}$ [23]. The release of these mediators results in the increase of vascular permeability, reduction of the nociception threshold and stimulation of nociceptive neurons sensitive to nonsteroidal anti-inflammatory drugs (NSAIDs) and opioids [24,25]. Indomethacin is a NSAID, it is able to inhibit PG synthesis which leads to peripheral analgesic effect [26]. In this study, indomethacin may have reduced PG and thromboxane synthesis from arachidonic acid by inhibiting the activity of cyclooxygenase (COX) enzymes [27]. Indomethacin has also been previously reported to reduce leukocytes recruitment and inhibits neutrophil accumulation [28], by extension blocks the voltage-gated calcium channel resulting in the blockage of $\mathrm{Ca}^{2+}$ influx and intracellular $\mathrm{Ca}^{2+}$-dependent mechanism [29]. Pretreatment of the rats with eicosane, pentadecane, octacosane, and heneicosane reduced the acetic acid-induced writhing response, and this analgesic role was similar to the effect observed with indomethacin (the reference drug). The result suggests that the compounds have the potential to inhibit the release and activation of mediators such as PG, TNF- $\alpha$, IL-1 $\beta$, IL-8, histamine, kinins, acetylcholine, and substance P. It may also have blocked cox enzymes or inhibit the leukocytes recruitment, inhibit neutrophil accumulation, as well as reduce the 
influx of intracellular calcium. Eicosane and pentadecane showed the highest effect.

\section{Formalin-induced paw licking}

The subcutaneous injection of diluted $(3.0 \%)$ formalin $(0.1 \mathrm{ml})$ into the subplantar surface induced a nociceptive response, characterized by an increase in licking time. The oral administration of increasing concentrations ( 5 and $10 \mathrm{mg} / \mathrm{kg}$ ) of eicosane, pentadecane, octacosane, and heneicosane did not show any significant reduction in the number of licking during the early phase. Eicosane, pentadecane, octacosane, and eicosane (at 5 and $10 \mathrm{mg} / \mathrm{kg}$ ) and indomethacin (at $10 \mathrm{mg} / \mathrm{kg}$ ) elicited significant reduction in the number of licking during the late phase. Eicosane and pentadecane showed the highest reduction and they are more potent than indomethacin. The results of formalininduced paw licking are shown in Fig. 3. The injection of formalin in the hind paw produced nociceptive responses involving two different phases [30]. The first phase, known as neurogenic pain, starts immediately after formalin injection (0-5 $\mathrm{min})$. This phase was due to the direct effect of formalin on sensory C fibers [31]. Earlier reports have suggested that substance $\mathrm{P}$ and bradykinin are involved in the first phase [32]. The first phase therefore reflects the centrally-mediated pain, which is usually suppressed by the $\mu$-opioid receptor agonist, morphine [33]. The second phase starts approximately $20 \mathrm{~min}$ after the formalin injection. It reflects the development of an inflammatory response to tissue injury associated with the release of nociceptive mediators [32]. It was reported that histamine, serotonin, PG, and bradykinin were released during the second phase [34]. The reference drug, indomethacin, inhibits the late phase significantly, and this was expected since indomethacin is a peripheral acting drug that inhibits the enzymatic activity of COX from facilitating the release of inflammatory mediators such as histamine, serotonin, PG, and bradykinin. Eicosane, pentadecane, octacosane, and heneicosane inhibit the late phase significantly, and the analgesic role was similar to the mechanism of action of the reference drug indomethacin. This finding suggests that they may be inhibiting the release of inflammatory mediators such as histamine, serotonin, PG, and bradykinin. They may also be interacting with cox enzymes. Eicosane and pentadecane at a dose of $5 \mathrm{mg}$ were more potent than indomethacin at $10 \mathrm{mg}$

\section{Carrageenan-induced paw edema}

Eicosane and pentadecane at 5 and $10 \mathrm{mg} / \mathrm{kg}$ and indomethacin $(10 \mathrm{mg} / \mathrm{kg})$ significantly inhibited carrageenan-induced rat paw edema $(\mathrm{p}<0.05)$. Octacosane and heneicosane (5 and $10 \mathrm{mg} / \mathrm{kg}$ ) did not show any significant inhibition on carrageenan-induced paw edema. The inhibitory values of edema were based on $5 \mathrm{~h}$ post-carrageenan treatment, Fig. 4.

The carrageenan-induced paw edema test has been widely used as an investigational model of acute inflammation. It has been reported that carrageenan is a useful phlogistic tool for testing anti-inflammatory drugs, especially NSAIDs [35]. The injection of carrageenan results in the release of nitric oxide (NO), tumor necrosis factor- $\alpha$ (TNF- $\alpha$ ), and IL-1 $\beta$ [36]. The release of these mediators causes vasodilatation, exudation of plasma and neutrophils migration to the site of injury [37]. The injection of carrageenan into the hind paw involves three phases. The first phase extends from 1 to $2 \mathrm{~h}$, which is mediated through the release of histamine, serotonin, and kinins [38]. The second phase starts after 2-4 h predominantly due to the release of kinins, plateletactivating factors, and arachidonic acid metabolites such as PGs, thromboxanes (TXs), and leukotrienes (LTs).

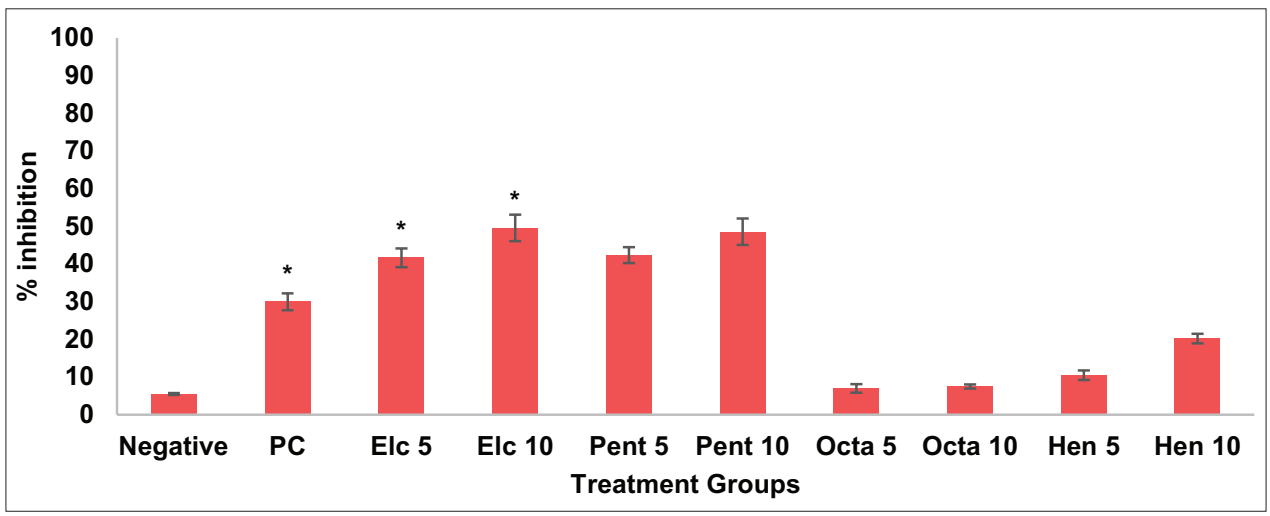

Fig. 3: Percentage inhibitions of formalin-induced paw licking, values are expressed as mean \pm Standard deviation, $n=6$, the statistical significance by one-way analysis of variance, followed by Dunnett's test. Values are significant at *p<0.05

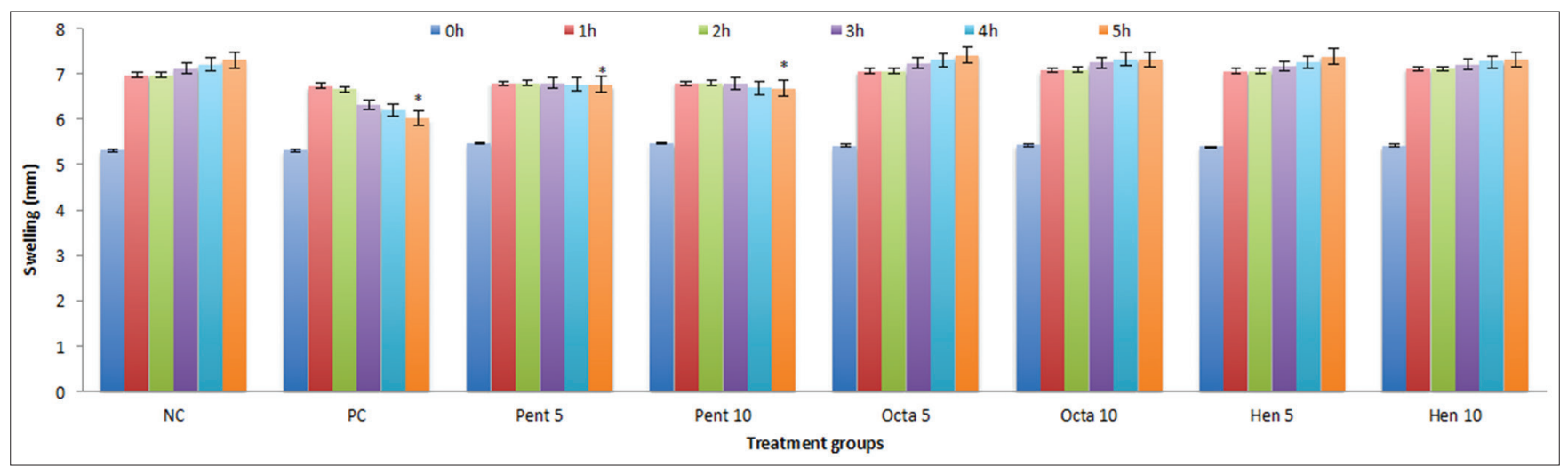

Fig. 4: Effects of the administration of eicosane, pentadecane, octacosane, heneicosane (5 and $10 \mathrm{mg} / \mathrm{kg})$, and indomethacin (10 mg/kg) on rat paw edema induced by intraplantar injection of $0.1 \mathrm{ml}$ of $1.0 \%$ carrageenan suspension. Values are expressed as mean \pm Standard deviation, $n=6$, the statistical significance by one-way analysis of variance, followed by Dunnett's test. Values are significant at *p<0.05 and ${ }^{\text {ns }} \mathrm{P}=$ Not significant compare to negative control when no drugs were given 


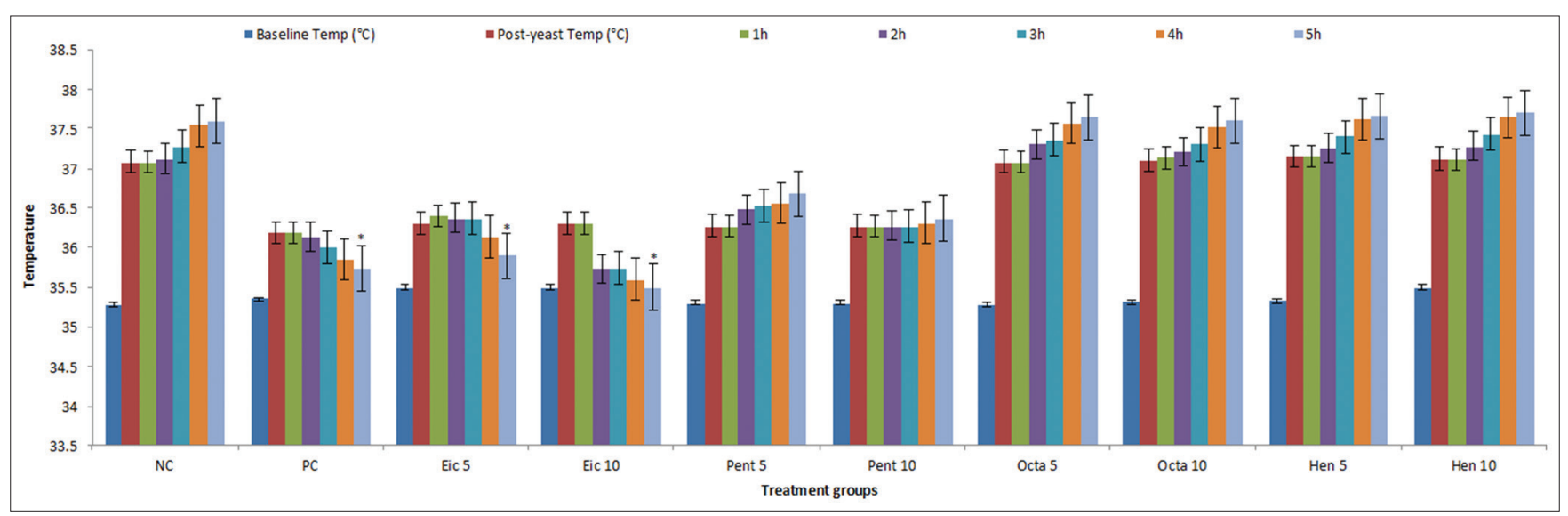

Fig. 5: Antipyretic effect of eicosane, pentadecane, octacosane, heneicosane (5 and $10 \mathrm{mg} / \mathrm{kg})$, and indomethacin (10 mg/ $\mathrm{kg}) \mathrm{on}$ rats induced by yeast. Values are expressed as mean \pm Standard deviation, $n=6$, the statistical significance by one-way analysis of variance, followed by Dunnett's test. Values are significant at ${ }^{*} \mathrm{p}<0.05$ and ${ }^{\mathrm{n}} \mathrm{P}=$ Not significant compare to negative control when no drugs were given

The release of these mediators causes TNF- $\alpha$ to release kinins and LTs and these results in the long-lasting nociceptive response [39]. The third phase starts at $4-5 \mathrm{~h}$ when the edema reaches its highest volume. The third phase is mediated by the release of bradykinin and overproduction of PGs, which lead to the formation of inflammatory exudates and hypersensitivity at the site of injury [40]. Oral administration of eicosane and pentadecane inhibited the three phases, suggesting that the inhibitory effect of eicosane and pentadecane on carrageenan-induced paw edema may be due to the inhibition of the release of an inflammatory mediator such as histamine, bradykinin, serotonin, kinins, and PGs. Octacosane and heneicosane did not show any effect. A previous report has shown that free fatty acids, including long-chain C16-C20 unsaturated fatty acids, have been suspected to be the bioactive components responsible for the anti-inflammatory activity reported in Tinospora smilacina Berth extract. Fatty acids can be of therapeutic value when infections are present in asthma patients (Desbois and Smith, 2010). This result is in line with the anti-asthmatic effect of purified leaf extract of MP reported by Okechukwu et al., Okechukwu and Ikujuni, and Ekeuku and Okechukwu [7,14,15].

\section{Yeast-induced pyrexia}

Subcutaneous injection of a yeast suspension resulted in a markedly elevated rectal temperature as measured $24 \mathrm{~h}$ after administration. Treatment with increasing concentrations of eicosane (5 and $10 \mathrm{mg} /$ $\mathrm{kg})$ and indomethacin $(10 \mathrm{mg} / \mathrm{kg})$ significantly $(\mathrm{p}<0.05)$ decreased the rectal temperature of the rats as compared to the control group. Pentadecane, octacosane, and heneicosane did not show any significant effect on decreasing the rectal temperature. The result of the antipyretic activity is shown in Fig. 5.

Subcutaneously injected yeast's cell wall products act as exogenous pyrogens and stimulate the immune cells, such as lymphocytes and macrophages [41]. The stimulation of immune cells results in the production of endogenous pyrogens in the form of cytokines such as TNF, IL-1b, IL-6, and interferon- $\alpha$ [42]. The cytokines enter the systemic circulation and increase the synthesis of PGE2 in the brain to elevate the hypothalamic set point for body temperature [43]. Reports show that COX-2 and iNOS are involved in the generation of a pyrexia response to brewer's yeast as the COX-2 isoform mediates pyrexia response through the production of E-type PG [44]. Therefore, a selective COX-2 antagonist is widely used due to its effectiveness in antipyretic activity [45]. The present study showed that the oral administration of indomethacin at $10 \mathrm{mg} / \mathrm{kg}$ exerted significant $(\mathrm{p}<0.05)$ antipyretic activity after the $2^{\text {nd }} \mathrm{h}$ of the treatment. Vane reported that indomethacin blocks the COX enzymes, therefore inhibiting the production of E-type PG. Indomethacin also reduces the elevation of the body temperature by inhibiting the inflammatory messages at the site of infection and within the thermoregulatory center [47]. It also reduces the production of pyrogenic cytokines, block leukocytes interactions, and diminishes the thermoregulatory set point by blocking PG E2-production [48]. Oral administration of eicosane produced a significant $(\mathrm{p}<0.05)$ hypothermal activity against yeast-induced pyrexia on rats, suggesting that the anti-inflammatory role was similar to indomethacin (reference drug) by suppressing the production of PG E2. Pentadecane, octacosane, and heneicosane did not show any effect.

\section{CONCLUSIONS}

Eicosane and pentadecane mimic the effect of indomethacin, except in an antipyretic test where pentadecane did not show any effect. The compounds were more potent than indomethacin in the formalininduced paw licking test. The compounds did not show any toxicity. Eicosane and pentadecane may be the major bioactive compound present in the fraction A extract of MP. The bioactive compounds may have inhibited the release of histamine, bradykinin, PGs, TXs, and LTs. They may have also reduced the stimulation of cytokines such as TNF, IL-1b, IL-6, and interferon- $\alpha$ and interacted with the cox enzyme. The effect is similar to the effect of the control drug indomethacin. The result is in consonance with an earlier report on purified leaf extract of MP.

\section{ACKNOWLEDGMENT}

The authors are grateful to FRGS Malaysia Ministry of Higher Education, Reference code: 2/2013/SG05/UCSI/02/1 and Innovation and Entrepreneurship Research Grant Scheme UCSI University (UCSICERVIE-RGS Proj-in-FAS 038) and for providing the grant for this research.

\section{AUTHORS' CONTRIBUTION}

The project was done and authored by Dr. Patrick Nwabueze Okechukwu.

\section{CONFLICTS OF INTEREST}

The authors confirm that this article content has no conflicts of interest.

\section{REFERENCES}

1. Harizal SN, Mansor SM, Hasnan J, Tharakan JK, Abdullah J. Acute toxicity study of the standardized methsanolic extract of Mitragyna speciosa Korth in rodent. J Ethnopharmacol 2010;131:404-9.

2. Atsamo AD, Nguelefack TB, Datté JY, Kamanyi A. Acute and subchronic oral toxicity assessment of the aqueous extract from the stem bark of Erythrina senegalensis DC (Fabaceae) in rodents. J Ethnopharmacol 2011;134:697-702.

3. Adedapo AA, Sofidiya MO, Maphosa V, Moyo B, Masika PJ, Afolayan AJ. Anti-inflammatory and analgesic activities of aqueous 
extract of Cussonia paniculata stem bark. Rec Nat Prod 2008;2:46-53.

4. Kim HP, Son KH, Chang HW, Kang SS. Anti-inflammatory plant flavonoids and cellular action mechanisms. J Pharmacol Sci 2004:96:229-45.

5. Jamal W, Mohammed MS, Ahmed WJ, Khalid HS, Mahmoud AM, Garelnabi EA. Di-(2'-ethylhexyl) phthalate and stigmasterol with antiinflammatory effect from Cyperus rotundus L. Int J Pharm Chem Biol Sci 2014;4:453-9.

6. Hisham DM, Lip JM, Noh JM, Normah A. Identification and isolation of methyl gallate as a polar chemical marker for Labisia pumila Benth. J Trop Agric Food Sci 2011;39:279-84.

7. Okechukwu PN, Ekeuku SO, Loshnie S, Akowuah GA. Antiinflammatory, analgesic, antinociceptive and antipyretic investigation of bioactive constituents from partial purified dichloromethane crude extracts from leaves of Labisia pumila. Int J Pharm Res Scholars 2014;3:743-51.

8. Stein SE. An integrated method for spectrum extraction. J Am Soc Mass Spectrom 1999;10:770-81.

9. Sharifi-Rad J, Seyedeh MH, Majid SR, Setzer WN. Chemical composition, antifungal and antibacterial activities of essential oil from Lallemantia royleana (Benth. in Wall.) Benth J Food Saf 2014;35:19-25.

10. Rana IS, Rana AS, Rajak RC. Evaluation of antifungal activity in essential oil of the Syzygium aromaticum (L.) by extraction, purification and analysis of its main component eugenol. Braz J Microbiol 2011;42:1269-77.

11. Sacchetti G, Maietti S, Muzzoli M, Scaglianti M, Manfredini S, Radice M, et al. Comparative evaluation of 11 essential oils of different origin as functional antioxidants, antiradicals and antimicrobials in foods. Food Chem 2005;91:621-32.

12. Samuagam L, Akowuah GA, Okechukwu PN. Partial purification and antinociceptive investigation of extracts of leaves of Labisia pumila. Asian J Pharm Clin Res 2011;4:44-6.

13. Sulaiman MR, Perimal EK, Akhtar MN, Mohamad AS, Khalid MH, Tasrip NA, et al. Anti-inflammatory effect of zerumbone on acute and chronic inflammation models in mice. Fitoterapia 2010;81:855-8.

14. Okechukwu PN, Ikujuni CM. The study of anti-inflammatory antipyretic and anti-nociceptive activities of extract from leaves of Labisia pumila. Int J Pharmacol Toxicol Sci 2012;2:12-27.

15. Ekeuku SO, Okechukwu PN. Paw edemaand bronchoconstriction induced by mediators: How they were inhibited in vivo by partially purified extract from dichloromethane leaf extract of Labisia pumila. Middle East J Sci Res 2014;22:1114-21.

16. Creton S, Dewhurst IC, Earl LK, Gehen SC, Guest RL, Hotchkiss JA, et al.Acute toxicity testing of chemicals-opportunities to avoid redundant testing and use alternative approaches. Crit Rev Toxicol 2010;40:50-83.

17. Akhila JS, Shyamjith D, Alwar MC. Acute toxicity studies and determination of median lethal dose. Curr Sci 2007;93:917-20.

18. Gad SC. Reference Module in Biomedical Sciences Encyclopedia of Toxicology. $3^{\text {rd }}$ ed. North Carolina: Elsevier; 2014. p. 58-60.

19. Bentley GA, Newton SH, Starr J. Evidence for an action of morphine and the enkephalins on sensory nerve endings in the mouse peritoneum. Br J Pharmacol 1981;73:325-32.

20. Siegmund E, Cadmus R, Lu G. A method for evaluating both non-narcotic and narcotic analgesics. Proc Soc Exp Biol Med 1957;95:729-31.

21. Satyanarayana PS, Jain NK, Singh A, Kulkarni SK. Isobolographic analysis of interaction between cyclooxygenase inhibitors and tramadol in acetic acid-induced writhing in mice. Prog Neuropsychopharmacol Biol Psychiatry 2004;28:641-9.

22. Wang MQ, Ge BS, Yang QX, Jiang XY, Huang F. High-level production of biologically active chemokines in Escherichia coli. Process Biochem 2014;49:706-714.

23. Demir Özkay U, Can OD. Anti-nociceptive effect of vitexin mediated by the opioid system in mice. Pharmacol Biochem Behav 2013;109:2330 .

24. Pinheiro MM, Bessa SO, Fingolo CE, Kuster RM, Matheus ME, Menezes FS, et al. Antinociceptive activity of fractions from Couroupita guianensis Aubl. Leaves. J Ethnopharmacol 2010;127:407-13.

25. Pinheiro MM, Boylan F, Fernandes PD. Antinociceptive effect of the Orbignya speciosa mart. (babassu) leaves: Evidence for the involvement of apigenin. Life Sci 2012;91:293-300.
26. Reuben S, Lopez M, Maciolek H, Fortunato A. NSAIDs and acetaminophen: Postoperative analgesic effects of celecoxib for spinal fusion surgery. J Pain 2004;5:S64.

27. Robinson C, Alfonso H, Woo S, Olsen N, Bill Musk AW, Robinson BW, et al. Effect of NSAIDS and COX-2 inhibitors on the incidence and severity of asbestos-induced malignant mesothelioma: Evidence from an animal model and a human cohort. Lung Cancer 2014;86:29-34.

28. Castro P, Nasser H, Abrahão A, Dos Reis LC, Riça I, Valença SS, et al. Aspirin and indomethacin reduce lung inflammation of mice exposed to cigarette smoke. Biochem Pharmacol 2009;77:1029-39.

29. Sadowsky DW, Haluska GJ, Gravett MG, Witkin SS, Novy MJ. Indomethacin blocks interleukin 1beta-induced myometrial contractions in pregnant rhesus monkeys. Am J Obstet Gynecol 2000;183:173-80.

30. Wheeler-Aceto $\mathrm{H}$, Cowan A. Neurogenic and tissue-mediated components of formalin-induced edema: Evidence for supraspinal regulation. Agents Actions 1991;34:264-9.

31. Hunskaar S, Hole K. The formalin test in mice: Dissociation between inflammatory and non-inflammatory pain. Pain 1987;30:103-14

32. Shibata M, Ohkubo T, Takahashi H, Inoki R. Modified formalin test: Characteristic biphasic pain response. Pain 1989;38:347-52.

33. Abbott FV, Franklin KB, Westbrook RF. The formalin test: Scoring properties of the first and second phases of the pain response in rats. Pain 1995;60:91-102.

34. Santos AR, Calixto JB. Further evidence for the involvement of tachykinin receptor subtypes in formalin and capsaicin models of pain in mice. Neuropeptides 1997;31:381-9.

35. Rachchh M, Yadav P, Gokani R, Jain S. Anti-inflammatory activity of Benincasa hispida fruit. Int J Pharm Bio Sci 2011;2:98-106.

36. Sadeghi H, Haijhashemi V, Minaiyan M, Movahedian A, Talebi A. Further studies on anti-inflammatory activity of maprotiline in carrageenan-induced paw edema in rat. Int Immunopharmacol 2013:15:505-10.

37. Reis EF, Castro SB, Alvesm CC, Oliveira EE, Correa TA, Almeida MV, et al. Lipophilic amino alcohols reduces carrageenan-induced paw edema and anti-OVA DTH in BALB/c mice. Int Immunopharmacol 2013;17:727-32.

38. Solanki HK, Shah DA, Maheriya PM, Patel CA. Evaluation of antiinflammatory activity of probiotic on carrageenan-induced paw edema in Wistar rats. Int J Biol Macromol 2015;72:1277-82.

39. Yun KJ, Koh DJ, Kim SH, Park SJ, Ryu JH, Kim DG, et al. Antiinflammatory effects of sinapic acid through the suppression of inducible nitric oxide synthase, cyclooxygase-2, and proinflammatory cytokines expressions via nuclear factor- $\mathrm{\kappa B}$ inactivation. J Agric Food Chem 2008;56:10265-72.

40. Tohda C, Nakayama N, Hatanaka F, Komatsu K. Comparison of anti-inflammatory activities of six curcuma rhizomes: A possible curcuminoid-independent pathway mediated by Curcuma phaeocaulis extract. Evid Based Complement Alternat Med 2006;3:255-60.

41. Saper CB, Breder CD. The neurologic basis of fever. N Engl J Med 1994;330:1880-6.

42. Luheshi, GN. Cytokines and fever. Mechanisms and sites of action. Ann N Y Acad Sci 1998;856:83-9.

43. Bhat AS, Tandan SK, Kumar D, Krishna V, Prakash VR. Interaction between inhibitors of inducible nitric oxide synthase and cyclooxygenase in Brewer's yeast induced pyrexia in mice: An isobolographic study. Eur J Pharmacol 2005;511:137-42.

44. Zhang YH, Elmquist JK, Saper CB. Specific roles of cyclooxygenase-1 and cyclooxygenase-2 in lipopolysaccharide-induced fever and fos expression in rat brain. J Comp Neurol 2003;463:3-12.

45. Simon LS. Role and regulation of cyclooxygenase-2 during inflammation. Am J Med 1999; 106:37S-42.

46. Vane JR. Inhibition of prostaglandin synthesis as a mechanism of action for aspirin-like drugs. Nat N Biol 1971;231:232-5.

47. Popovich PG, Tovar CA, Wei P, Fisherm L, Jakeman LB, Basso DM. A reassessment of a classic neuroprotective combination therapy for spinal cord injured rats: LPS/pregnenolone/indomethacin. Exp Neurol 2012;233:677-85.

48. Aronoff DM, Neilson EG. Antipyretics: Mechanisms of action and clinical use in fever suppression. Am J Med 2001;111:304-15. 